\title{
Criminalidade nos municípios do Rio de Janeiro: uma análise multivariada e espacial ${ }^{*}$
}

\author{
Criminality in the Municipalities of the State of Rio de Janeiro: a Multivariate \\ and Spatial Analysis
}

\author{
Priscila Soares dos Santos, Évilly Carine Dias Bezerra, Clailton Ataídes de \\ Freitas e Kalinca Léia Becker**
}

\begin{abstract}
Resumo: O objetivo deste trabalho é analisar a distribuição espacial e o fenômeno do crime nos municípios fluminenses, em 2006, 2010 e 2016. Para isso, foram construídos três Índices de Criminalidade, independentes entre si, a partir da técnica multivariada de análise fatorial por componentes principais. Após, utilizou-se a análise exploratória dos dados espaciais para verificação da distribuição espacial da criminalidade. Assim, foi possível observar que os municípios com maior criminalidade estão concentrados espacialmente na Região Metropolitana do estado, onde foi encontrado um cluster principal do tipo alto-alto. Os clusters do tipo baixo-baixo localizaram-se principalmente nas regiões Serrana, Centro Fluminense e Noroeste Fluminense.
\end{abstract}

Palavras-chave: Crime; Autocorrelação espacial; Clusters

\begin{abstract}
The objective of this article is to analyze the spatial distribution and the crime in the cities of Rio de Janeiro, in 2006, 2010 and 2016. Therefore, the factor analysis was used to construct a three Crime Indexes, independent of each other. Then, the exploratory analysis of spatial data was used to verify the spatial distribution of crime. Thus, it is possible to observe that the municipalities with higher crime are spatially concentrated in the metropolitan region of the state, where was found a main cluster of high-high type. The low-low clusters were mainly located in the Serrana, Centro Fluminense and Noroeste Fluminense regions.
\end{abstract}

Keywords: Crime; Spatial autocorrelation; Clusters

JEL: K42; C38; D01

\footnotetext{
* Submissão: 13/02/2020 | Aprovação: 31/08/2020 | DOI: 10.5380/re.v42i78.71723

** Respectivamente: (1) Doutoranda em Economia Aplicada na Escola Superior de Agricultura Luiz de Queiroz da Universidade de São Paulo (Esalq), Brasil |E-mail: soarespriscila@usp.br |ORCID: 0000-00027313-3651 | (2) Mestre em Economia e Desenvolvimento pela Universidade Federal de Santa Maria (UFSM), Brasil | E-mail: evillycarine@hotmail.com | ORCID: 0000-0002-9876-6260 | (3) Professor do Departamento de Economia e Relações Internacionais da Universidade Federal de Santa Maria (UFSM), Brasil | E-mail: lcv589@gmail.com | ORCID: 0000-0003-0754-3211 | (4) Professora do Departamento de Economia e Relações Internacionais da Universidade Federal de Santa Maria (UFSM), Brasil | E-mail: kalincabecker@gmail.com | ORCID: 0000-0002-6896-9411
} 


\section{Introdução}

A criminalidade é um fenômeno usualmente estudado em diferentes áreas e através de diferentes abordagens. Desde que Becker (1968) considerou o crime como uma atividade econômica, mesmo que ilícita, o campo de estudos deste fenômeno ganhou espaço nas Ciências Econômicas, principalmente nos estudos da área da Economia Social.

Buscando compreender melhor o fenômeno, alguns trabalhos como o de Araújo Junior e Fajnzlber (2001) se propuseram a tentar explicar os determinantes da criminalidade. Destarte, algumas relações entre condições econômicas e sociais e níveis de criminalidade começaram a ser testadas ao longo do tempo. Questões como rendimentos, desemprego, desigualdade social, pobreza e interação social passaram a ser tratadas como possíveis explicações para a ocorrência de crimes econômicos (Cerqueira; Moura, 2015; Procópio; Toyoshima, 2017). Além dessas, o tamanho das cidades foi outra variável testada nos modelos econométricos que buscavam explicar este fenômeno, como demonstra o trabalho de Oliveira (2005).

A questão espacial também passou a ser levada em consideração ao se falar em criminalidade. A ideia de que esta não se distribui de forma homogênea entre os diferentes espaços abriu margem para o avanço tanto de teorias quanto de técnicas específicas para verificar as diferentes hipóteses. Peixoto, Moro e Andrade (2004) argumentam que esta distribuição se concentra nas maiores cidades, Uchôa e Menezes (2012) também corroboram com esse argumento em sua pesquisa, mas chamam a atenção para o fato disso estar mudando ao longo do tempo.

No Brasil, o crescimento da criminalidade, em todas as suas formas, vem sendo alvo de atenção entre os formuladores de políticas de segurança pública. $\mathrm{O}$ aumento deste fenômeno pode afetar não somente o estilo de vida e o bem-estar da sociedade, mas também as atividades econômicas, como, por exemplo, o turismo. Além de alguns efeitos negativos que podem causar em diferentes setores da economia, o aumento da criminalidade pode aumentar os gastos com segurança pública em determinada localidade (Becker; Kassouf, 2017). Desta forma, o crime se comporta como um fenômeno complexo e que carrega consigo custos sociais e econômicos.

Assim sendo, a criminalidade vem se tornando um problema social que é cada vez mais alvo de grande atenção no país e no mundo. No caso brasileiro, os dados do Anuário Brasileiro de Segurança Pública demonstram que, no ano de 
2018, o Brasil contou com cerca de 57.341 casos registrados de mortes violentas. No que diz respeito aos crimes contra o patrimônio, o número de casos registrados de roubos de rua foi de 490.456, sendo o estado do Rio de Janeiro responsável por 130.620 deles.

A criminalidade no estado do Rio de Janeiro, principalmente na Região Metropolitana, apresenta ainda um caráter peculiar. A área, além de ser acometida por elevados índices de corrupção e de crimes de colarinho branco na esfera política, conta ainda com organizações criminosas tais como o jogo do bicho e as milícias. Conforme explica Misse (2011), tanto as milícias quanto o jogo do bicho surgiram no Rio de Janeiro e vêm sendo adotados em cidades de outros estados do Brasil.

Os municípios fluminenses contam ainda com o grande problema dos elevados níveis de tráfico de drogas. Este tipo de crime, associado a um caráter de crime organizado, busca sempre ampliar sua área de atuação em busca de novos mercados consumidores. No caso do município do Rio de Janeiro, a grande repressão existente sobre esse tipo de crime força a ida dele para diferentes localidades, podendo afetar a incidência do crime em diferentes áreas (Uchôa; Menezes, 2012). Desta forma, os elevados indicadores de criminalidade no estado, e o seu crescimento ao longo dos anos, constituem um desafio constante para o poder público.

Diante disso, tem-se o seguinte problema: a criminalidade dos municípios do Rio de Janeiro é espacialmente correlacionada? Tem-se por hipótese no presente trabalho que a dependência espacial se faz presente. Para buscar a resposta desta problemática, o objetivo geral do estudo é analisar a distribuição espacial e o fenômeno do crime nos municípios fluminenses, em 2006, 2010 e 2016. Os objetivos específicos incluem: construir Índices de Criminalidade (IC) para os municípios em questão nesses três anos, identificar a distribuição espacial destes índices no estado do Rio de Janeiro e verificar a formação de clusters espaciais locais.

A fim de se alcançarem os objetivos propostos, foram utilizadas no presente artigo técnicas multivariadas de análise fatorial por componentes principais para a construção dos índices de criminalidade, nos três períodos de análise. O método adotado, apesar de eficiente para a geração dos índices, pode possuir limitações ao se considerar a questão temporal. Desta forma, serão construídos no estudo três diferentes índices que, apesar de não comparáveis, demarcam o fenômeno do crime no Rio de Janeiro nos três períodos do tempo analisados, de forma isolada e 
independente. $\mathrm{O}$ transbordamento espacial do crime entre os municípios do estado do Rio de Janeiro é estimado usando análise exploratória de dados espaciais (AEDE) para verificar a existência de clusters espaciais de criminalidade no estado.

Espera-se que o presente trabalho possa contribuir com a identificação do perfil e da distribuição do fenômeno da criminalidade entre os diferentes municípios do Rio de Janeiro, com a informação de cada período analisado, a fím de se verificar se o crime se encontra espacialmente correlacionado no estado. Assim, almeja-se que desta forma os gestores de segurança pública consigam direcionar as políticas entre os municípios fluminenses de forma mais eficaz.

$\mathrm{Na}$ medida em que este trabalho conta com uma base de dados ainda pouco explorada, que está melhor detalhada na Seção 3 do presente estudo, com a construção de um índice geral de criminalidade e, ainda, com a AEDE para analisar a criminalidade no Rio de Janeiro, esta pesquisa busca contribuir com o debate acadêmico neste aspecto, visto que os estudos de Misse (2011) e Silva Júnior (2016) analisam a criminalidade no Rio de Janeiro, porém com outro enfoque, o primeiro com uma análise sobre as relações dos crimes organizados e comuns, já o segundo faz uma análise das políticas de segurança pública, não foram encontrados estudos que propusessem a construção de um índice de criminalidade para o estado do Rio de Janeiro combinada com a AEDE.

Diante disso, o presente estudo conta, além dessa seção introdutória, com algumas considerações sobre a economia do crime na Seção 2. Na seção 3, encontra-se a metodologia utilizada no trabalho e, logo após, na Seção 4, estão os resultados obtidos com a pesquisa. Por fim, na Seção 5, estão as conclusões às quais foi possível chegar com o estudo.

\section{Considerações sobre a economia do crime}

Esta seção está dividida em duas subseções. Na primeira, apresenta-se a fundamentação da teoria econômica do crime. A segunda subseção, por sua vez, conta com algumas evidências empíricas acerca do crime econômico.

\subsection{Fundamentos teóricos da economia do crime}

Gary Becker (1968) e Isaac Ehrlich (1973) abordaram em seus trabalhos a criminalidade como um processo de decisão individual no contexto dos modelos de escolha racional. O artigo seminal de Gary Becker (1968) intitulado "Crime 
and Punishment: an Economic Aproach" foi o propulsor da teoria econômica do crime. $\mathrm{O}$ autor abordou a criminalidade como um processo de decisão individual no contexto dos modelos de escolha racional. Desta forma, a escolha racional do indivíduo de cometer ou não o crime irá depender da utilidade esperada com o ato criminoso. Caso o risco de ser punido supere os ganhos a serem obtidos com o ato criminoso, o indivíduo seria desestimulado a cometer o crime.

Gary Becker (1968) propôs a equação da escolha racional, que relaciona o número de ofensas cometidas por um indivíduo à função da probabilidade de condenação deste mesmo indivíduo, formalmente:

$$
o_{j}=o_{j}\left(p_{j} ; f_{j} ; u_{j}\right)
$$

onde $O_{j}$ é o número de ofensas cometidas pelo indivíduo $j$ em determinado período, $p_{j}$ é a probabilidade de condenação do indivíduo $j, f_{j}$ é a condenação do indivíduo pelo ato criminoso e $u_{j}$ o resíduo representado por todas as outras variáveis que influenciam a decisão do indivíduo para o ato criminoso.

Diante disso, quanto maior a probabilidade de prisão e condenação dos indivíduos que cometem o crime, maiores são também os custos envolvidos ao optar pela atividade ilícita. Ou seja, a diferença entre os custos e os benefícios para cada agente são determinantes da sua decisão de se cometer ou não um crime.

Ao incluir em seu modelo de escolha racional a noção de custo de oportunidade, Becker (1968) destacou a importância do emprego e da renda para se reduzir a criminalidade. Para o autor, enquanto atividades ilegais lucrativas (como, por exemplo, o tráfico de drogas) tenderiam a estimular o indivíduo a cometer o crime, maiores oportunidades de emprego e salários atrativos no mercado formal de trabalho podem ajudar o indivíduo a optar por não ingressar na vida criminosa. Essa relação entre emprego e criminalidade também foi abordada em trabalhos como os de Cantor e Land (1985) e Cerqueira e Moura (2015).

Isaac Ehrlich (1973) propôs que o indivíduo decide sua alocação de tempo entre atividades legais e ilegais. $\mathrm{O}$ autor tratou o ingresso na atividade criminosa como uma escolha sob incerteza, onde as pessoas respondem a incentivos e decidem iniciar ou não a atividade ilegal. Ademais, buscou mostrar a relação existente entre desigualdade de renda e crimes contra o patrimônio, tratando o ato criminoso com retornos econômicos como uma escolha ocupacional. 
Considerando o crime como um fenômeno complexo e de difícil explicação, algumas abordagens do campo da sociologia também tentaram buscar explicações para a incidência de criminalidade. Em exemplo, tem-se as teorias da desorganização social, do controle social, da associação diferencial e a teoria interacional.

A teoria da desorganização social trata as relações sociais, como as de amizade, como essenciais para o desenvolvimento do indivíduo enquanto parte de uma determinada comunidade. O processo de socialização seria, portanto, importante para o desenvolvimento da virtude ética dos indivíduos. Já a teoria do controle social busca compreender o motivo pelo qual as pessoas deixam de cometer crimes. Novamente, a questão do envolvimento social dos indivíduos é levada em consideração. Desta forma, quanto maiores forem os elos da pessoa com a sociedade e maiores os graus de concordância com valores e normas vigentes, menores são as chances dessa pessoa de cometer atos criminosos (Cerqueira; Lobão, 2004; Procópio; Toyoshima, 2017).

A teoria da associação diferencial, proposta por Edwin Sutherland (1924), trata da influência a que os indivíduos podem estar expostos e que podem levá-los a cometer um crime. Os indivíduos, neste caso, podem tornar-se criminosos após a associação àqueles que já cometem crimes. Assim, a atividade criminosa seria aprendida através da experiência. A teoria interacional, também, encara o comportamento criminoso como sendo influenciado por uma variedade de relações desenvolvidas ao longo do tempo (Entorf; Spengler, 2002).

Diante das diferentes abordagens teóricas que procuram explicar o fenômeno da criminalidade, alguns autores dedicaram seus trabalhos para buscar verificar algumas das hipóteses propostas. Diante disso, algumas evidências empíricas existentes acerca da teoria do crime estão apresentadas na seção abaixo.

\subsection{Evidências empíricas da incidência do crime}

Buscando encontrar explicações para o fenômeno do crime, alguns autores passaram a incorporar em seus trabalhos possíveis efeitos de condições socioeconômicas na incidência de criminalidade. Andrade e Lisboa (2001) verificaram uma relação entre taxas de homicídio e variáveis socioeconômicas como a desigualdade de renda e a escolaridade, de modo que uma melhor distribuição de renda estaria associada a uma diminuição deste tipo de crime. 
Estudos como os de Shikida (2008) e Resende e Andrade (2011) também corroboram com esses resultados.

Seguindo a linha da escolha racional proposta por Becker (1968), trabalhos como os de Araújo Junior e Fajnzybler (2001), Santos e Kassouf (2008) e Philip e Land (2012) procuraram demonstrar a relação existente entre emprego e criminalidade. Os autores destacam a possível relação ambígua existente entre ambos. Enquanto um vínculo empregatício formal pode diminuir as chances de um indivíduo ingressar no crime, pois aumenta seu custo de oportunidade, pode, também, tornar esses indivíduos vítimas mais economicamente atrativas para as pessoas propensas a cometer o ato criminoso. Isso se dá principalmente porque maiores vínculos no emprego formal, normalmente, estão também associados a maiores rendimentos.

Ainda, esta mesma relação ambígua pode ser encontrada no que tange à escolaridade, visto que esta, normalmente, se traduz em melhores empregos e maiores rendimentos, conforme explicam Becker e Kassouf (2017). As evidências encontradas pelas autoras indicaram que os gastos com educação contribuem para diminuir as taxas de homicídios nos estados brasileiros no longo prazo. Esse resultado vai do encontro com os de Araújo e Fajnzylber (2000), que evidenciaram que um aumento da escolaridade é capaz de diminuir os crimes contra a pessoa, no entanto, possuem uma relação positiva com os crimes contra o patrimônio. Oliveira (2005) ainda relacionou o tamanho das cidades à ocorrência de crimes.

A literatura ainda apresenta algumas evidências que relacionam a desorganização social ao aumento da criminalidade. Os problemas gerados pelas crises e más condições demográficas, urbanização descontrolada e questões ligadas à deterioração dos espaços urbanos abandonados pelo poder público, bem como os desajustes sociais que podem ser ocasionados por famílias mal estruturadas, seriam possíveis causas da criminalidade para Procópio e Toyoshima (2017), que argumentam que a violência resultaria da frustração dos indivíduos privados da realização de seus objetivos sociais.

Para além da relação entre as variáveis socioeconômicas e demográficas com a criminalidade, um outro fator que deve ser levado em consideração é a questão espacial. Os trabalhos de Oliveira (2008) e de Saraiva et al. (2016) se propuseram a analisar a dependência espacial das taxas de crime nos municípios do Rio Grande do Sul. 
Waiselfisz (2011) chama a atenção para um possível efeito de interiorização da criminalidade. De acordo com o autor, a partir do fim da década de 90 as cidades do interior e de médio porte passaram conviver com níveis cada vez maiores de violência.

Em Minas Gerais, Faria et al. (2008) e Gomes et al. (2017) encontraram a formação de aglomerações espaciais da criminalidade no estado, sendo que estas se deram de forma diferenciada entre os crimes contra a pessoa e os crimes contra o patrimônio. Outros trabalhos que analisaram a relação espacial do crime nos municípios mineiros foram os de Batella e Diniz (2010), Castro et al. (2014) e Moreira e Fochezatto (2017), bem como Plassa e Parré (2019) que se utilizaram da análise fatorial e da AEDE para analisar o comportamento das taxas de homicídio no Paraná.

No Rio de Janeiro, apesar do vasto histórico de ocorrências de crimes no estado, poucos são os trabalhos que se dedicaram a analisar de forma aplicada o fenômeno na região. Szwarcwald e Castilho (1998) fizeram uma análise espacial acerca da mortalidade por armas de fogo no estado do Rio de Janeiro no período de 1979 e 1992, onde encontraram uma difusão da ocorrência da mortalidade para o interior do estado ao longo do período.

Como exposto, a literatura relacionada ao crime é vasta e aborda diferentes vertentes desde explicações mais relacionadas à interação social, fatores morais, até a fatores mais favoráveis à medição, como a educação, renda e empregabilidade. Deste modo, os procedimentos metodológicos adotados no estudo estão dispostos na próxima seção.

\section{Metodologia}

Esta seção contempla informações sobre as variáveis, fonte de dados e período analisados. Além disso, detalha o método estatístico multivariado e o método econométrico espacial, com seus respectivos testes de hipótese, bem como softwares utilizados.

\subsection{Fonte e base de dados}

Os dados utilizados na análise fatorial foram fornecidos pelo Instituto de Segurança Pública do Rio de Janeiro (ISP-RJ), disponibilizados através de solicitação dos autores. Neste trabalho foram utilizados os dados para os anos de 2006, 2010 e 2016 para a verificação em um intervalo de 10 anos do índice de criminalidade no tempo, em três momentos. 
Quadro 1 - Descrição, período e fonte das variáveis utilizadas

\begin{tabular}{|c|c|c|c|}
\hline Variável & Descrição & Ano & Fonte \\
\hline $\mathrm{X} 1$ & $\begin{array}{l}\text { Apreensão de drogas (casos, percentual por } 100.000 \\
\text { habitantes do município) }\end{array}$ & \multirow{15}{*}{$\begin{array}{c}2006 \\
2010 \\
2016\end{array}$} & \multirow{15}{*}{ ISP-RJ } \\
\hline $\mathrm{X} 2$ & $\begin{array}{l}\text { Furto a transeunte (casos, percentual por } 100.000 \\
\text { habitantes do município) }\end{array}$ & & \\
\hline X3 & $\begin{array}{l}\text { Furto de telefone celular (casos, percentual por } \\
100.000 \text { habitantes do município) }\end{array}$ & & \\
\hline $\mathrm{X} 4$ & $\begin{array}{l}\text { Furto de veículos (casos, percentual por } 100.000 \\
\text { habitantes do município) }\end{array}$ & & \\
\hline $\mathrm{X} 5$ & $\begin{array}{l}\text { Furto em coletivo (casos, percentual por } 100.000 \\
\text { habitantes do município) }\end{array}$ & & \\
\hline X6 & $\begin{array}{l}\text { Homicídio doloso (vítimas, percentual por } 100.000 \\
\text { habitantes do município) }\end{array}$ & & \\
\hline $\mathrm{X} 7$ & $\begin{array}{l}\text { Latrocínio (vítimas, percentual por } 100.000 \text { habitantes } \\
\text { do município) }\end{array}$ & & \\
\hline X8 & $\begin{array}{l}\text { Roubo a estabelecimento comercial (casos, percentual } \\
\text { por } 100.000 \text { habitantes do município) }\end{array}$ & & \\
\hline X9 & $\begin{array}{l}\text { Roubo a residência (casos, percentual por } 100.000 \\
\text { habitantes do município) }\end{array}$ & & \\
\hline $\mathrm{X} 10$ & $\begin{array}{l}\text { Roubo a transeunte (casos, percentual por } 100.000 \\
\text { habitantes do município) }\end{array}$ & & \\
\hline X11 & $\begin{array}{l}\text { Roubo após saque (casos, percentual por } 100.000 \\
\text { habitantes do município) }\end{array}$ & & \\
\hline $\mathrm{X} 12$ & $\begin{array}{l}\text { Roubo de carga (casos, percentual por } 100.000 \\
\text { habitantes do município) }\end{array}$ & & \\
\hline X13 & $\begin{array}{l}\text { Roubo de celular (casos, percentual por } 100.000 \\
\text { habitantes do município) }\end{array}$ & & \\
\hline X14 & $\begin{array}{l}\text { Roubo de veículo (casos, percentual por } 100.000 \\
\text { habitantes do município) }\end{array}$ & & \\
\hline $\mathrm{X} 15$ & $\begin{array}{l}\text { Roubo em coletivo (casos, percentual por } 100.000 \\
\text { habitantes do município) }\end{array}$ & & \\
\hline
\end{tabular}

Fonte: elaboração própria, a partir de ISP-RJ (2019).

Essas variáveis foram escolhidas por resumirem os diferentes tipos de crimes de um local por motivação econômica e, portanto, permitirem a construção de um indicador geral da criminalidade. As variáveis, por caso ou vítimas, foram ponderadas por taxa de 100.000 habitantes, na forma:

$$
\text { percentual da variável }=\frac{\text { variável observada }}{\text { população municipal }} \times 100.000
$$


As variáveis utilizadas na presente pesquisa passaram pela ponderação expressa na equação (2) para que as análises não fossem tendenciosas, principalmente para municípios populosos.

Cabe ressaltar que, do total dos municípios fluminenses, Aperibé, Areal, Arraial do Cabo, Carapebus, Comendador Levy Gasparian, Cardoso Moreira, Guapimirim, Italva, Macuco, Paty dos Alferes, Quatis, Quissamã, São José de Ubá, Tanguá e Varre-Sai não possuíam informações para todos os três anos analisados no presente estudo. Assim, para o ano de 2006 o índice foi construído tendo um total de 77 municípios, já para os anos de 2010 e 2016, foram somadas 79 e 82 observações, respectivamente.

\subsection{Uma breve apresentação do modelo multivariado}

$\mathrm{O}$ índice de criminalidade foi construído com o uso de análise fatorial (AF) usando componentes principais.

A análise de componentes principais é uma técnica multivariada que permite a geração de fatores não correlacionados através de combinações lineares das variáveis iniciais, o resultado desse método de determinação de fatores é utilizado pela AF (Fávero; Belfiore, 2017).

A AF é uma técnica de interdependência que possui como propósito principal a definição de uma estrutura inerente entre variáveis na análise (HAIR Jr. et al., 2009). Esta técnica, conforme explica Mingoti (2005), possibilita a redução de muitas variáveis em um menor número de fatores que não são correlacionados entre si. Isso pode ser demonstrado na equação abaixo:

$$
Z_{p}=l_{p 1} F_{1}+l_{p 2} F_{2}+\cdots+l_{p j} F_{j}+\varepsilon_{p}
$$

em que $Z_{p}$ são as variáveis observadas, $l_{p}$ são as chamadas cargas fatoriais, os fatores comuns não correlacionados são representados por $F_{j}$ e o termo de erro é dado por $\varepsilon_{p}$. Neste caso, a variação de cada variável é explicada por um fator de variabilidade comum e um elemento de variação específico. Logo, o termo de erro corresponde aos erros de medição e não pode ser explicado pelos fatores comuns.

O Índice de Criminalidade para os municípios do Rio de Janeiro $\left(I C_{m}\right)$ é construído a partir dos scores fatoriais. Seguindo os procedimentos generalizados por Mingoti (2005), formalmente, tem-se: 


$$
I C_{m}=\sum_{j=1}^{p}\left(\frac{\sigma j^{2}}{\sum_{j=1}^{p} \sigma^{2} j} F_{j m}\right)
$$

onde $I C_{m}$ é o índice de criminalidade do m-ésimo município do Rio de Janeiro, $\sigma^{2}$ é a variância explicada pelo fator $j ; p$ é o número de fatores escolhidos; $\sum_{j=1}^{p} \sigma^{2} j$ representa o somatório das variâncias explicadas pelos $p$ fatores extraídos e $F_{j m}$ é o escore fatorial do município $m$, do fator $j$. A equação (4) implica que os fatores que compõem os índices são ponderados por suas respectivas variâncias, que podem apresentar mudanças ao longo do tempo e, desta forma, inviabilizar comparações dos índices nos diferentes anos.

Com o fito dos índices estarem no intervalo fechado de 0 a 1 , foi realizada a padronização dos resultados, equação (5), para que as saídas não sejam menores que 0 ou maiores que 1 .

$$
I C_{m}=\frac{I C_{m}-I C_{\min }}{I C_{m a ́ x}-I C_{\min }}
$$

em que, $I C_{\min }$ é o índice mínimo calculado, e $I C_{\text {máx }}$ é o índice máximo calculado. Desse modo, o $I C_{m}$ varia entre os valores 0 e 1 , sendo que quanto mais próximo de 1 , maior a incidência de criminalidade.

Para verificar se a AF é do ponto de vista estatístico sustentada para estimar a base de dados descritas no quadro 1 , foram realizados os testes de Kaiser-MeyerOlkin (KMO) e o Barlett Test of Sphericity (BTS) ou Teste de Esfericidade de Bartlett. O KMO é representado por Fávero e Belfiore (2017) na forma:

$$
K M O=\frac{\sum_{l=1}^{k} \sum_{c=1}^{k} \rho_{l c}^{2}}{\sum_{l=1}^{k} \sum_{c=1}^{k} \rho_{l c}^{2}+\sum_{l=1}^{k} \sum_{c=1}^{k} \varphi_{l c}^{2}}
$$

Consoante Mingoti (2005), o KMO pode variar entre 0 e 1, mas é recomendado que o resultado do referido teste seja acima de 0,7 e, preferencialmente, igual ou maior que 0,8 para que a base de dados esteja apropriada para estudar o fenômeno em questão, já o BTS possui o objetivo de verificar se a matriz de correlações é igual à uma matriz identidade, testando as seguintes hipóteses:

$$
\left\{\begin{array}{l}
H_{0}: P_{p X p}=I_{p X p} \\
H_{1}: P_{p X p} \neq I_{p X p}
\end{array}\right.
$$


Fávero e Belfiore (2017) destacam que o teste de esfericidade de Bartlett, segue uma distribuição Qui-quadrada que pode ser expressa como:

$$
\mathrm{X}_{\text {Bartlett }}^{2}=\left[(n-1)-\left(\frac{2 k+5}{6}\right)\right] \ln |\mathrm{D}|
$$

em que: $P_{p X p}$ é a matriz de correlação e $I_{p X p}$ é a matriz identidade. Logo, para que os dados sejam adequados, deve-se rejeitar $H_{0}$.

Foi adotado o método de rotação fatorial ortogonal varimax, que segundo Hair Junior et al. (2009) potencializa a soma das variâncias das cargas fatoriais, o resultado é uma visualização mais clara de como as variáveis estão associadas e quanto esta característica reflete positiva ou negativamente em cada fator.

Para a obtenção dos resultados da análise fatorial por componentes principais, os resultados dos procedimentos apresentados, testes e método de rotação varimax, foi utilizado o software Stata ${ }^{\circledR} 15$.

Cabe salientar novamente que o método adotado pode apresentar limitações ao se levar em consideração o efeito do tempo, visto que as variáveis podem apresentar níveis de relevância diferentes em cada ano e, no caso específico do presente estudo, a quantidade de municípios analisados varia nos diferentes períodos, de acordo com a disponibilidade de dados. Diante disso, a construção dos índices requer a aplicação do método ano a ano, ao invés de considerar todos os anos ao mesmo tempo na geração dos resultados. Desta forma, devido à possível limitação do método no que se refere à comparação temporal, o presente estudo se limitará a analisar, sem uma análise comparativa, três diferentes índices em retratos distintos: 2006, 2010 e 2016. Uma possível comparação iria demandar o uso de uma AF dinâmica ou longitudinal como método multivariado.

Os índices obtidos na Análise Fatorial foram utilizados na Análise Exploratória dos Dados Espaciais (AEDE) a fim de se verificar a existência e distribuição de clusters espaciais de criminalidade entre os municípios nos diferentes anos da pesquisa. Assim, torna-se possível fazer uma análise acerca da mudança da distribuição espacial do crime no Rio de Janeiro ao longo do tempo.

\subsection{Procedimento econométrico espacial}

Para a realização da Análise Exploratória dos Dados Espaciais (AEDE), foi calculada a estatística I de Moran global e a estatística I de Moran local. 
Partindo das recomendações de Almeida (2012) para a AEDE, o I de Moran Global é dado por:

$$
I=\frac{n}{S_{0}} \frac{\sum_{i} \sum_{j} w_{i j} z_{i} z_{j}}{\sum_{i=1}^{n} z_{i}^{2}}
$$

em que $n$ representa o número de regiões; $z$ representa as variáveis padronizadas; $S_{0}$ é igual a $\sum_{i} \sum_{j} w_{i j}$, indicando que as entradas da matriz de pesos espaciais $w$ serão somados; $w_{z}$ denota a média das variáveis padronizadas nos vizinhos, através de uma matriz de ponderação espacial $w$.

Se o resultado dessa estatística for positivo, indica que há similaridade entre as variáveis e o espaço, de forma que locais com altos valores de determinada variável são rodeados por locais com valores altos e vice-versa, ou seja, existe efeito transbordamento. Caso seja negativo, locais com altos valores são rodeados por locais com baixos valores e vice-versa, numa força aumentada à medida que a estatística I de Moran global se aproxima de 1. A inferência realizada consiste em realizar a permutação aleatória com a geração do Pseudo p-valor com as seguintes hipóteses:

$$
\left\{\begin{array}{c}
H_{0}: \text { aleatoriedade espacial } \\
H_{1}: \text { ausência de aleatoriedade espacial }
\end{array}\right.
$$

Já o I de Moran Local (LISA) calculado para a verificação de clusters espaciais é definido por Anselin (1995), como:

$$
I=\sum_{i} I_{i} /\left[S_{0}\left(\sum_{i} z_{i}^{2} / n\right)\right]
$$

em que as siglas seguem o mesmo significado já apresentado na equação (8). Esse resultado é testado por permutação aleatória, tendo por hipótese nula a não existência do cluster espacial.

Para a realização dos testes, da construção dos mapas e geração dos resultados da AEDE foram utilizados os softwares livres GeoDa e QGis 3.10. Os resultados obtidos com os procedimentos metodológicos adotados estão apresentados na próxima seção. 


\section{Resultados e discussão}

Nesta seção estão os resultados obtidos com o presente estudo. Para tal, a organização dos resultados está dividida em duas subseções, de modo que a primeira contempla o cálculo do índice de criminalidade $\left(I C_{m}\right)$ para os municípios do Rio de Janeiro e a segunda subseção refere-se à análise exploratória dos dados espaciais, onde se verifica os níveis de autocorrelação espacial do $I C_{m}$.

\section{1. Índice de Criminalidade dos Municípios do Rio de Janeiro $\left(I C_{m}\right)$}

A verificação que precede a estimação dos fatores comuns, centrada nos testes de $\mathrm{KMO}$ e de Bartlett, resultaram em valores de KMO superiores a 0,8, o que é considerado excelente segundo Mingoti (2005) e em valores de Bartlett que apontam para resultados estatisticamente significativos em todo o período, assim, a hipótese nula de matriz identidade foi rejeitada, indicando a existência de correlação entre as variáveis. Os resultados dos testes indicam, portanto, que a análise fatorial por componentes principais é adequada para o estudo. Esses resultados estão dispostos na Tabela 1.

Tabela 1 - Estatística KMO e Teste de Bartlett

\begin{tabular}{cccc}
\hline \multirow{2}{*}{ Ano } & \multicolumn{3}{c}{ Estatística KMO } \\
\cline { 2 - 4 } & $\mathbf{2 0 0 6}$ & $\mathbf{2 0 1 0}$ & $\mathbf{2 0 1 6}$ \\
\hline Overall & 0.8439 & 0.8435 & 0.8336 \\
Teste Bartlett & 927.01 & 873.81 & 951.16 \\
P-valor & 0.0000 & 0.0000 & 0.0000 \\
\hline
\end{tabular}

Fonte: elaborado pelos autores.

Os resultados dos testes foram capazes de confirmar, portanto, que, mesmo com a existência de limitações no método ao se levar em consideração o efeito do tempo, o uso da análise fatorial por componentes principais foi adequado para a criação dos três distintos índices de criminalidade. Dada a aplicabilidade adequada da metodologia adotada, passou-se então para a estimativa dos fatores comuns. Para a rotação, o método utilizado foi o varimax, que maximiza a variância do fator. Com base nos quinze indicadores analisados, foi possível obter os fatores que compuseram os índices de criminalidades para os anos de 2006, 2010 e 2016.

Ao proceder a interpretação separada dos resultados dos índices por período, no ano de 2006, foi possível extrair três fatores, que foram capazes de 
captar 69,17\% da variância acumulada das variáveis. O critério utilizado para a determinação do número de fatores a serem extraídos se deu com base nos valores das raízes características maior do que um. As raízes características de cada fator para os anos de 2006, 2010 e 2016, juntamente com as suas variâncias explicadas, podem ser observadas na Tabela 2.

\section{Tabela 2 - Resultado da análise fatorial, raiz característica e variância explicada para os anos de 2006, 2010 e 2016}

\begin{tabular}{c|ccc|ccc|ccc}
\hline \multirow{2}{*}{ Fator } & Eigenvalue & Prop. & Acum. & Eigenvalue & Prop. & Acum. & Eigenvalue & Prop. & Acum. \\
\cline { 2 - 11 } & \multicolumn{3}{|c|}{$\mathbf{2 0 0 6}$} & \multicolumn{3}{|c|}{$\mathbf{2 0 1 0}$} & \multicolumn{3}{c}{$\mathbf{2 0 1 6}$} \\
\hline F1 & 7,0162 & 0,4677 & 0,4677 & 6,8830 & 0,4589 & 0,4589 & 6,9746 & 0,4650 & 0,4650 \\
F2 & 2,1076 & 0,1405 & 0,6083 & 1,9874 & 0,1325 & 0,5914 & 1,8592 & 0,1239 & 0,5889 \\
F3 & 1,2520 & 0,0835 & 0,6917 & 1,2717 & 0,0848 & 0,6761 & 1,3254 & 0,0884 & 0,6773 \\
F4 & - & - & - & - & - & - & 1,0668 & 0,0711 & 0,7484 \\
\hline
\end{tabular}

Nota: Prop. = variância explicada. Acum. = variância acumulada.

Fonte: elaborado pelos autores com base nos resultados da pesquisa.

Em 2010, três fatores também foram extraídos. Juntos, eles foram suficientes para explicar mais de $67,00 \%$ da massa de variância dos dados. Novamente, os fatores extraídos são os que possuem raízes características maiores do que um. No ano de 2016, diferente dos outros dois anos, foram encontrados quatros fatores com raízes características maiores do que um. Neste caso, os fatores foram responsáveis por explicar, conjuntamente, cerca de $74,84 \%$ da variância total.

A rotação ortogonal pelo método varimax permitiu que fossem encontrados os coeficientes de correlação entre variáveis e os fatores e as comunalidades de cada variável. Os valores das cargas fatoriais, bem como os respectivos fatores gerados em cada ano, estão dispostos para observação nas próximas três tabelas. Conforme destaca a literatura, é recomendada a seleção de cargas fatoriais maiores que 0,5 (Ferreira Júnior et al., 2004; Mingoti, 2005). A fim de se encontrar resultados mais robustos, o presente trabalho analisa as cargas fatoriais acima de 0,6 em cada fator.

No ano de 2006, o Fator 1, que representa cerca de 46,77\% da variância total dos dados (Tabela 2), está relacionado com as variáveis furto a transeunte (X2), furto em coletivo (X5), roubo a transeunte (X10), roubo após saque (X11), roubo de celular (X13), roubo de veículos (X14) e roubo em coletivo (X15). O Fator 2, por sua vez, explica 14,05\% da variância dos dados e está relacionado com 
a apreensão de drogas (X1), furto de telefone celular (X3) e roubo a estabelecimento comercial (X8). Já o terceiro fator, responsável por explicar $8,35 \%$ da variância (Tabela 2), se relaciona apenas com a variável referente a roubo a residência. Essas agregações estão apresentadas na Tabela 3.

Tabela 3 - Cargas fatoriais e comunalidades para o $I C_{m}$ (2006)

\begin{tabular}{ccccc}
\hline Variável & Fator $\mathbf{1}$ & Fator 2 & Fator 3 & Comunalidades \\
\hline X1 & $-0,2602$ & $\mathbf{0 , 7 9 5 5}$ & $-0,0748$ & 0,7061 \\
X2 & $\mathbf{0 , 7 1 0 3}$ & 0,5157 & 0,0438 & 0,7723 \\
X3 & 0,2983 & $\mathbf{0 , 7 5 5 3}$ & $-0,0846$ & 0,6666 \\
X4 & 0,5791 & 0,4749 & 0,3236 & 0,6656 \\
X5 & $\mathbf{0 , 8 0 1 3}$ & 0,3693 & 0,1757 & 0,8093 \\
X6 & 0,3311 & 0,4889 & 0,5650 & 0,6679 \\
X7 & 0,1560 & $-0,0864$ & 0,5850 & 0,3740 \\
X8 & 0,3609 & $\mathbf{0 , 6 4 7 8}$ & 0,3803 & 0,6945 \\
X9 & 0,0696 & 0,3304 & $\mathbf{0 , 7 0 8 5}$ & 0,6160 \\
X10 & $\mathbf{0 , 9 4 8 4}$ & 0,1827 & 0,0591 & 0,9363 \\
X11 & $\mathbf{0 , 8 5 1 1}$ & $-0,0120$ & 0,0650 & 0,7287 \\
X12 & 0,2219 & 0,1737 & $-0,4062$ & 0,2444 \\
X13 & $\mathbf{0 , 9 4 6 9}$ & 0,0317 & $-0,0519$ & 0,9003 \\
X14 & $\mathbf{0 , 9 2 3 6}$ & 0,0535 & 0,0058 & 0,8558 \\
X15 & $\mathbf{0 , 8 2 4 7}$ & 0,1001 & 0,2189 & 0,7380 \\
\hline
\end{tabular}

Fonte: elaborado pelos autores com base nos resultados da pesquisa.

Após a obtenção dos scores fatoriais dos diferentes fatores, em 2006, conforme mostrado na Tabela 3, foi construído o índice de criminalidade para os municípios do Rio de Janeiro no ano citado. Desta forma, o índice construído varia de 0 a 1 , de modo que quanto mais próximo de 1 , maior a incidência de criminalidade naquela determinada localidade. Assim sendo, os municípios que apresentaram os cinco maiores índices foram: Niterói, Rio de Janeiro, Nilópolis, Armação dos Búzios e Duque de Caxias, respectivamente. De modo contrário, os cinco municípios com menores índices de criminalidade são: Rio das Flores, Engenheiro Paulo de Frontin, Natividade, São José do Vale do Rio Preto e Laje do Muriaé, respectivamente.

Em 2010, o primeiro fator, responsável por $45,89 \%$ da variância, se relacionou com o furto a transeunte (X2), furto de telefone celular (X3), furto de 
veículos (X4), furto em coletivo (X5), roubo a estabelecimento comercial (X8), roubo a transeunte (X10), roubo de celular (X13), roubo de veículos (X14) e roubo em coletivo (X15). Já o Fator 2, que explica cerca de 13,25\% da variância, mostrou-se relacionado com o latrocínio $(X 7)$ e o roubo a residência (X9). Enquanto isso, o Fator 3 esteve relacionado com a apreensão de drogas (X1), com o roubo após saque (X11) e com o roubo de carga (X12). Esses resultados podem ser melhor visualizados na Tabela 4.

Tabela 4 - Cargas fatoriais e comunalidades para o $I C_{m}(2010)$

\begin{tabular}{ccccc}
\hline Variável & Fator $\mathbf{1}$ & Fator 2 & Fator 3 & Comunalidades \\
\hline X1 & $-0,1296$ & 0,3380 & $\mathbf{- 0 , 6 3 9 1}$ & 0,5394 \\
X2 & $\mathbf{0 , 8 9 7 7}$ & 0,1671 & 0,0043 & 0,8338 \\
X3 & $\mathbf{0 , 6 1 7 0}$ & 0,5491 & $-0,0880$ & 0,6900 \\
X4 & $\mathbf{0 , 6 7 6 4}$ & 0,3466 & 0,2444 & 0,6374 \\
X5 & $\mathbf{0 , 8 3 1 7}$ & 0,0526 & 0,1259 & 0,7104 \\
X6 & 0,5377 & 0,3617 & 0,0589 & 0,4234 \\
X7 & $-0,0951$ & $\mathbf{0 , 6 0 4 4}$ & $-0,0207$ & 0,3748 \\
X8 & $\mathbf{0 , 6 4 2 8}$ & 0,5095 & 0,1007 & 0,6830 \\
X9 & 0,1075 & $\mathbf{0 , 8 2 0 1}$ & 0,0238 & 0,6846 \\
X10 & $\mathbf{0 , 8 9 7 7}$ & $-0,0094$ & 0,2630 & 0,8752 \\
X11 & 0,3561 & 0,0280 & $\mathbf{0 , 6 8 7 7}$ & 0,6005 \\
X12 & 0,0562 & 0,2274 & $\mathbf{0 , 8 1 0 4}$ & 0,7116 \\
X13 & $\mathbf{0 , 8 7 2 2}$ & $-0,1132$ & 0,1616 & 0,7996 \\
X14 & $\mathbf{0 , 8 3 4 3}$ & $-0,0635$ & 0,3943 & 0,8556 \\
X15 & $\mathbf{0 , 8 2 3 3}$ & $-0,0817$ & 0,1961 & 0,7230 \\
\hline
\end{tabular}

Fonte: elaborado pelos autores com base nos resultados da pesquisa.

Em 2010 os municípios com maior $I C_{m}$ foram: Rio de Janeiro, Niterói, Nilópolis, Macaé e Duque de Caxias, respectivamente. Em contrapartida, os municípios Trajano de Moraes, São José do Vale do Rio Preto, Natividade, Laje do Muriaé e Cambuci, apresentarem os menores índices de criminalidade, respectivamente.

O índice de 2016 apresentou a formação de quatro fatores. O Fator 1 se mostrou relacionado com as variáveis que se referem ao furto a transeunte (X2), furto em coletivo (X5), roubo a transeunte (X10), roubo após saque (X11), roubo de carga (X12), roubo de celular (X13), roubo de veículos (X14) e roubo em 
coletivo (X15). Já o Fator 2 se relaciona com o homicídio doloso (X6), com o roubo a estabelecimento comercial (X8), com o roubo a residência (X9). As cargas fatoriais, as comunalidades e as relações citadas dos fatores com as variáveis estão dispostas na Tabela 5 .

Tabela 5 - Cargas fatoriais e comunalidades para o $I C_{m}(2016)$

\begin{tabular}{cccccc}
\hline Variável & Fator $\mathbf{1}$ & Fator 2 & Fator 3 & Fator 4 & Comunalidades \\
\hline X1 & $-0,3555$ & 0,1010 & $\mathbf{0 , 6 2 3 9}$ & $-0,2676$ & 0,5975 \\
X2 & $\mathbf{0 , 8 0 1 7}$ & 0,0952 & 0,3085 & 0,2463 & 0,7569 \\
X3 & 0,0947 & $-0,0234$ & $\mathbf{0 , 8 8 3 8}$ & 0,2463 & 0,8513 \\
X4 & 0,2822 & 0,3051 & 0,2225 & $\mathbf{0 , 6 4 3 6}$ & 0,6365 \\
X5 & $\mathbf{0 , 7 5 6 6}$ & 0,1352 & 0,3071 & 0,0409 & 0,6867 \\
X6 & 0,2251 & $\mathbf{0 , 6 9 2 6}$ & $-0,1599$ & 0,2369 & 0,6121 \\
X7 & 0,1433 & 0,0424 & $-0,0474$ & $\mathbf{0 , 8 8 5 1}$ & 0,8080 \\
X8 & 0,5611 & $\mathbf{0 , 6 4 5 1}$ & $-0,0977$ & 0,1372 & 0,7594 \\
X9 & $-0,0920$ & $\mathbf{0 , 8 2 3 3}$ & 0,2560 & $-0,0300$ & 0,7527 \\
X10 & $\mathbf{0 , 9 2 8 5}$ & 0,1451 & $-0,1100$ & 0,2034 & 0,9366 \\
X11 & $\mathbf{0 , 8 0 4 1}$ & 0,0230 & 0,0018 & 0,1829 & 0,6805 \\
X12 & $\mathbf{0 , 7 9 0 1}$ & 0,0480 & $-0,2703$ & 0,0553 & 0,7026 \\
X13 & $\mathbf{0 , 8 8 3 6}$ & 0,1411 & $-0,0715$ & 0,2360 & 0,8615 \\
X14 & $\mathbf{0 , 8 7 4 1}$ & 0,1016 & $-0,1916$ & 0,2649 & 0,8813 \\
X15 & $\mathbf{0 , 8 0 9 6}$ & 0,1135 & $-0,1703$ & 0,0726 & 0,7026 \\
\hline
\end{tabular}

Fonte: elaborado pelos autores com base nos resultados da pesquisa.

Ainda de acordo com a Tabela 5, é possível observar que neste ano o terceiro fator se relaciona com as variáveis referentes a apreensão de drogas (X1) e ao furto de telefone celular (X3). Por fim, o Fator 4 apresentou relação com o furto de veículos (X4) e com o latrocínio (X7). Desta forma, os municípios com maiores índices de criminalidade em 2016 foram: Rio de Janeiro, Nilópolis, Mesquita, Niterói e São João de Meriti, respectivamente enquanto os menores índices estão localizados em Trajano de Moraes, Sumidouro, Santa Maria Madalena, São José do Vale do Rio Preto e Rio das Flores, respectivamente.

Diante dos resultados do $I C_{m}$ de 2006, 2010 e 2016, mesmo que os índices não conversassem entre si pelo método aplicado, foi possível verificar que o crime no Rio de Janeiro se concentra, principalmente, na Região Metropolitana nos três diferentes índices analisados. Algo esperado, já que há maior renda per capita e, 
portanto, maior expectativa de retorno da prática criminosa. Esse resultado é corroborado pelos estudos de Becker (1968), Isaac Ehrlich (1973) e Oliveira (2005). Os municípios com maiores e menores valores nos três $I C_{m}$ no período analisado se localizam em espaços próximos - resultado corroborado pelo fato de a metodologia adotada não considerar comparabilidade ao tratar cada ano de forma isolada -, o que sugere que existe uma zona de influência espacial da criminalidade e que ela pode se espalhar de um município para outro, ou o contrário, em que existem municípios com baixa criminalidade relativa que são próximos, essa característica também foi destacada nos trabalhos de Uchôa e Menezes (2012).

De forma descritiva, quanto aos tipos de grupos de crimes mais relacionados em cada setor, foi verificado que tipos de crimes que eram pouco relacionados, no índice de 2006, como roubo a residência, roubo de carga, furto de veículo, roubo a estabelecimento comercial, tiveram proximidade com outros crimes nos índices de 2010 e de 2016. Além disso, foi verificada grande associação entre diversas modalidades de roubo e furto nos diferentes períodos analisados. Esses resultados podem ser fruto dos diferentes pesos que as variáveis podem ter em cada ano, e também podem sugerir que a prática criminosa pode ser mutável e que a experiência e interação entre diferentes indivíduos que cometem crimes favorece a troca de aprendizagem e experiências numa situação de learning by doing, em que quanto maior o tempo na prática criminosa, maior a chance do aprimoramento do crime e diversificação de atuação, situação também discutida por Sutherland (1924) e por Entorf e Spengler (2002).

Conforme destacado na seção 1 do presente trabalho, a criminalidade não é um fenômeno de distribuição espacial homogênea. A fim de se verificar se essas constatações se estendem para os municípios do Rio de Janeiro, realizou-se no presente estudo uma análise espacial dos índices construídos para os três diferentes anos analisados.

\subsection{Análise exploratória de dados espaciais (AEDE)}

Antes de se avançar para a análise espacial, pode-se verificar que de fato a distribuição espacial do crime no Rio de Janeiro não se dá de forma homogênea. Nas três figuras a seguir está apresentada a distribuição dos índices de criminalidade para os anos de 2006, 2010 e 2016, respectivamente. Desta forma, as áreas foram coloridas de acordo com os valores apresentados em cada índice, sendo a cor mais 
clara referente aos municípios com menores $I C_{m}$. Os municípios que apresentam os maiores índices estão representados pelas tonalidades mais escuras.

Figura 1 - Distribuição dos índices de criminalidade nos municípios do Rio de Janeiro (2006)

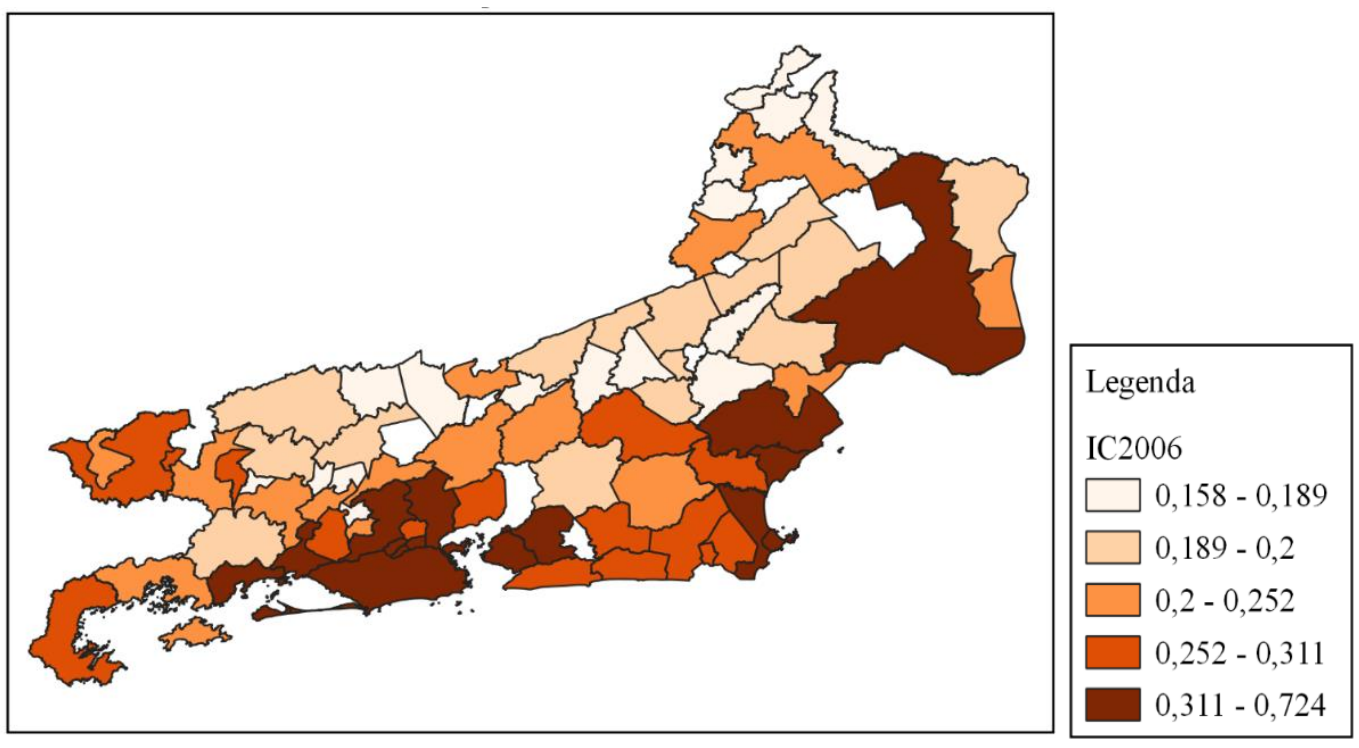

$$
\begin{aligned}
& \text { SRC: SIRGAS } 2000 \\
& \begin{array}{l}
\text { Malha digital: IBGE (2010) } \\
\text { Software: QGIS } 3.10 \\
\text { Elaborado pelos autores, a partir } \\
\text { dos resultados da pesquisa. }
\end{array}
\end{aligned}
$$

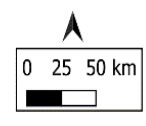

Fonte: elaborado pelos autores no software QGIS 3.10 a partir dos resultados da pesquisa.

A distribuição espacial do índice de 2006 permite a verificação de uma maior concentração dos crimes na região Metropolitana do estado e na região Norte Fluminense. Também se verificou uma alta incidência do índice de criminalidade na mesorregião das Baixadas Litorâneas, como no município de Cabo Frio, por exemplo. Um cenário parecido pode ser observado no índice construído para o ano de 2010, conforme mostra a Figura 2. 
Figura 2 - Distribuição dos índices de criminalidade nos municípios do Rio de Janeiro (2010)

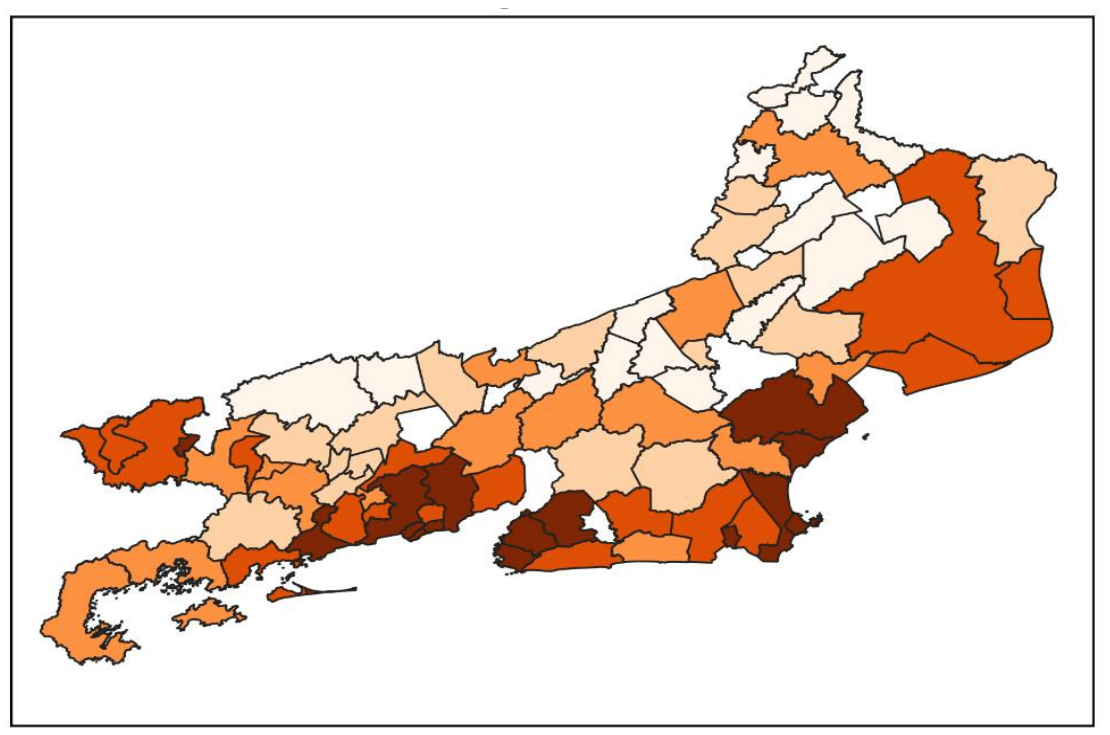

Legenda

IC2010

$0,128-0,164$

$0,164-0,205$

$0,205-0,245$

$0,245-0,312$

$0,312-0,692$

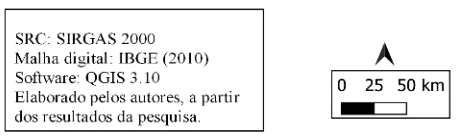

Fonte: elaborado pelos autores no software QGIS 3.10 a partir dos resultados da pesquisa.

O índice do ano de 2010 é espacialmente distribuído de forma desigual e encontra seus níveis mais elevados nos municípios das regiões Metropolitana e das Baixadas Litorâneas. Esses resultados podem ser explicados devido à alta densidade demográfica existente nessas regiões. Conforme demonstrou Oliveira (2005), o tamanho e a densidade das cidades é capaz de explicar parte da criminalidade existente em uma determinada localidade. Assim sendo, a alta concentração do crime na Região Metropolitana não é uma surpresa.

O índice construído para o ano de 2016 apresentou alta incidência de crime nos municípios que englobam as regiões Metropolitana, Norte Fluminense e das Baixadas Litorâneas do estado. Na Figura 3, é possível observar como o índice de criminalidade do ano de 2016 está distribuído espacialmente no estado. 
Figura 3 - Distribuição dos índices de criminalidade nos municípios do Rio de Janeiro (2016)

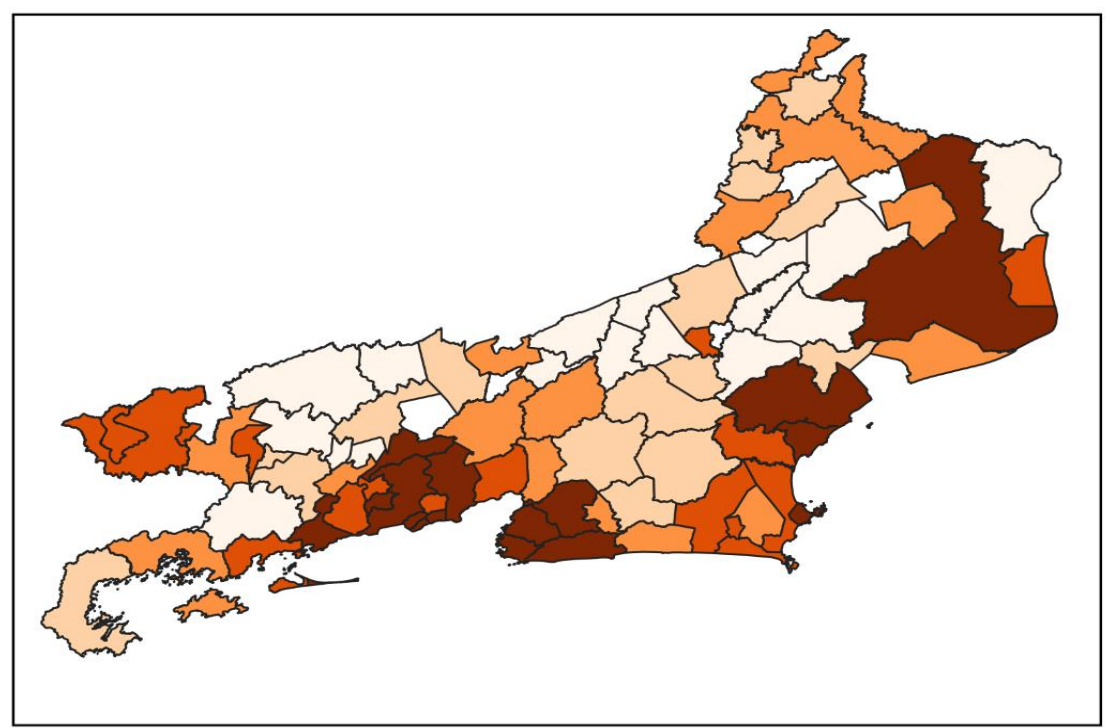

Legenda

IC2016

$0,122-0,179$

$0,179-0,224$

$0,224-0,258$

$0,258-0,334$

$0,334-0,733$

SRC: SIRGAS 2000

Malha digital: IBGE (2010)

Software: QGIS 3.10

Elaborado pelos autores, a partir

dos resultados da pesquisa

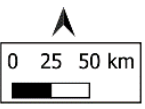

Fonte: elaborado pelos autores no software QGIS 3.10 a partir dos resultados da pesquisa.

Para além da alta densidade demográfica, a Região Metropolitana do Rio de Janeiro conta ainda com diversos problemas criminais como o tráfico de drogas, a formação de milícias e elevados índices de corrupção, conforme destacado por Misse (2011), que podem influenciar de forma direta ou indireta outros tipos de crime.

Os municípios da mesorregião das Baixadas Litorâneas, por sua vez, contam com uma grande população flutuante oriunda do turismo, forte atividade econômica na região (CEPERJ, 2019). Conforme explica Salgado (2017), o aumento do fluxo de pessoas ocasionado pelo crescente turismo na região, pode ter trazido consigo o aumento da desigualdade, impulsionando também a ocorrência de crimes nas Baixadas Litorâneas.

Os menores valores dos três índices observados localizam-se bem espalhados no território do estado do Rio de Janeiro, contemplando principalmente municípios das mesorregiões Noroeste e Centro Fluminense, em exemplo tem-se os municípios de Carmo e Sapucaia. Essas duas mesorregiões, além de possuírem uma menor densidade demográfica, também ficam atrás das mesorregiões Metropolitana e das Baixadas Litorâneas no que diz respeito à dinâmica econômica. 
Apesar dos mapas apresentarem uma distribuição espacial dos diferentes índices de criminalidade de forma dessemelhante entre os diversos municípios nos anos em questão, faz-se necessário analisar a presença da correlação espacial também através dos ferramentais I de Moran global e I de Moran local para cada índice construído.

\subsubsection{I de Moran Global}

Para haver a confirmação da correlação espacial calculou-se o I de Moran global univariado usando as convenções de matriz de contiguidade queen (rainha) e rook (torre). Diante dos resultados obtidos, que podem ser observados na Tabela 6 , é possível afirmar que o $I C_{m}$ é autocorrelacionado espacialmente entre os municípios do Rio de Janeiro na medida em que a hipótese nula de aleatoriedade espacial foi rejeitada nos três anos do presente estudo, seja para a matriz de contiguidade queen (rainha) ou rook (torre).

Tabela 6 - Coeficiente I de Moran global univariado do índice de criminalidade nos municípios do Rio de Janeiro em 2006, 2010 e 2016

\begin{tabular}{c|c|c|c|c|c|c}
\hline \multirow{2}{*}{ Convenção } & \multicolumn{3}{|c|}{ I de Moran } & \multicolumn{3}{c}{ P-valor* } \\
\cline { 2 - 7 } & $\mathbf{2 0 0 6}$ & $\mathbf{2 0 1 0}$ & $\mathbf{2 0 1 6}$ & $\mathbf{2 0 0 6}$ & $\mathbf{2 0 1 0}$ & $\mathbf{2 0 1 6}$ \\
\hline Rainha & 0,4942 & 0,5204 & 0,6590 & 0,001 & 0,001 & 0,001 \\
Torre & 0,4944 & 0,5212 & 0,6610 & 0,001 & 0,001 & 0,001 \\
5 vizinhos & 0,4685 & 0,4993 & 0,6345 & 0,001 & 0,001 & 0,001 \\
6 vizinhos & 0,4234 & 0,4726 & 0,6120 & 0,001 & 0,001 & 0,001 \\
\hline
\end{tabular}

Nota: * pseudo-significância baseado em 999 permutações aleatórias.

Fonte: elaboração própria.

A partir dos resultados apresentados na Tabela 6, é possível observar ainda que foi encontrada uma autocorrelação espacial positiva para os anos da análise através de ambas as matrizes de contiguidade. Esses efeitos se confirmam ainda após a análise dos diagramas de dispersão de Moran na Figura 4 a seguir. 
Figura 4 - Índice de Moran local do $I C_{m}$ para os municípios do Rio de Janeiro (2006, 2010 e 2016)

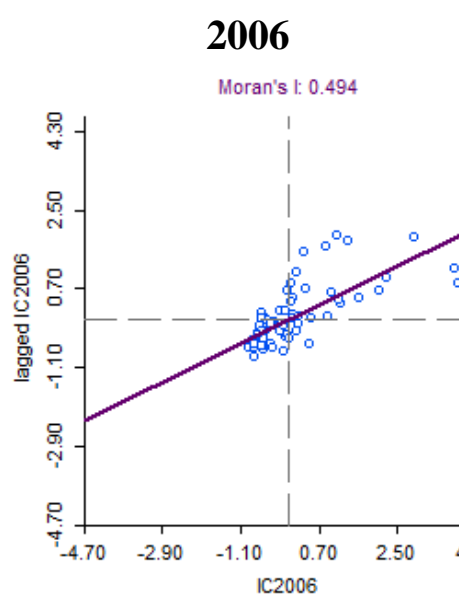

I de Moran = 0,494

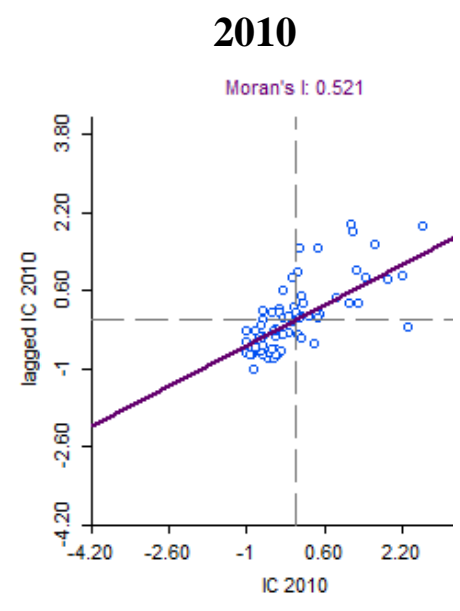

I de Moran = 0,521

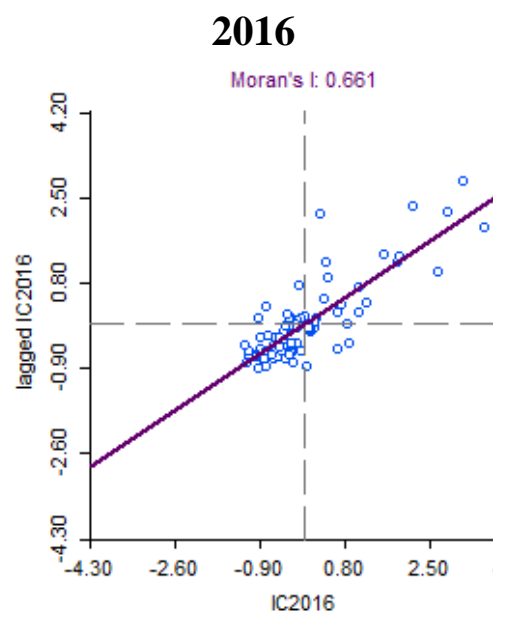

I de Moran = 0,661

Fonte: elaborado pelos autores com software GeoDa.

Para que o padrão de distribuição espacial seja mais facilmente notado, decompõe-se o I de Moran em quadrantes. Conforme explica Almeida (2012), embora os padrões globais de associação espacial possam estar, também, em consonância com os padrões locais, não necessariamente isso irá acontecer. As estatísticas de autocorrelação global não possuem capacidade suficiente para que haja a confirmação da ocorrência de autocorrelação local. Portanto, faz-se necessário a realização de uma estatística que capte este efeito. Para tal, calculouse o I de Moran Local.

\subsubsection{I de Moran Local}

Sendo capaz de capturar os padrões locais de associação espacial, o I de Moran local faz uma decomposição em quatro diferentes quadrantes do indicador global de autocorrelação na contribuição local das observações. Essa decomposição se dá de modo que o quadrante superior esquerdo localiza os municípios com baixa criminalidade, mas com vizinhos com alta criminalidade (baixo-alto). Enquanto isso, os municípios com alta criminalidade, mas com vizinhos com baixa criminalidade (alto-baixo) estão localizados no quadrante inferior direito.

O padrão considerado alto-alto, que agrupa municípios com alta criminalidade cujos vizinhos também possuem elevada criminalidade, localiza-se 
no quadrante superior direito. Já as aglomerações do tipo baixo-baixo, ou seja, que reúnem municípios com baixas taxas de criminalidade cujos vizinhos também possuem criminalidade baixa, estão dispostas no quadrante inferior esquerdo.

Após a decomposição, a significância estatística dos padrões locais é combinada com as informações do diagrama de dispersão (Figura 2), de modo que assim permite-se a verificação da existência de clusters espaciais da criminalidade entre os municípios do Rio de Janeiro. Desta forma, as aglomerações podem se dar de modo que municípios com altas taxas de criminalidade estejam próximos uns dos outros, municípios com baixas taxas de criminalidade estejam próximos, ou até mesmo de forma combinada. Na Figura 5 estão os mapas de formação de clusters no Rio de Janeiro para os anos de 2006.

Figura 5 - Clusters espaciais do $I C_{m}$ nos municípios do Rio de Janeiro (2006)

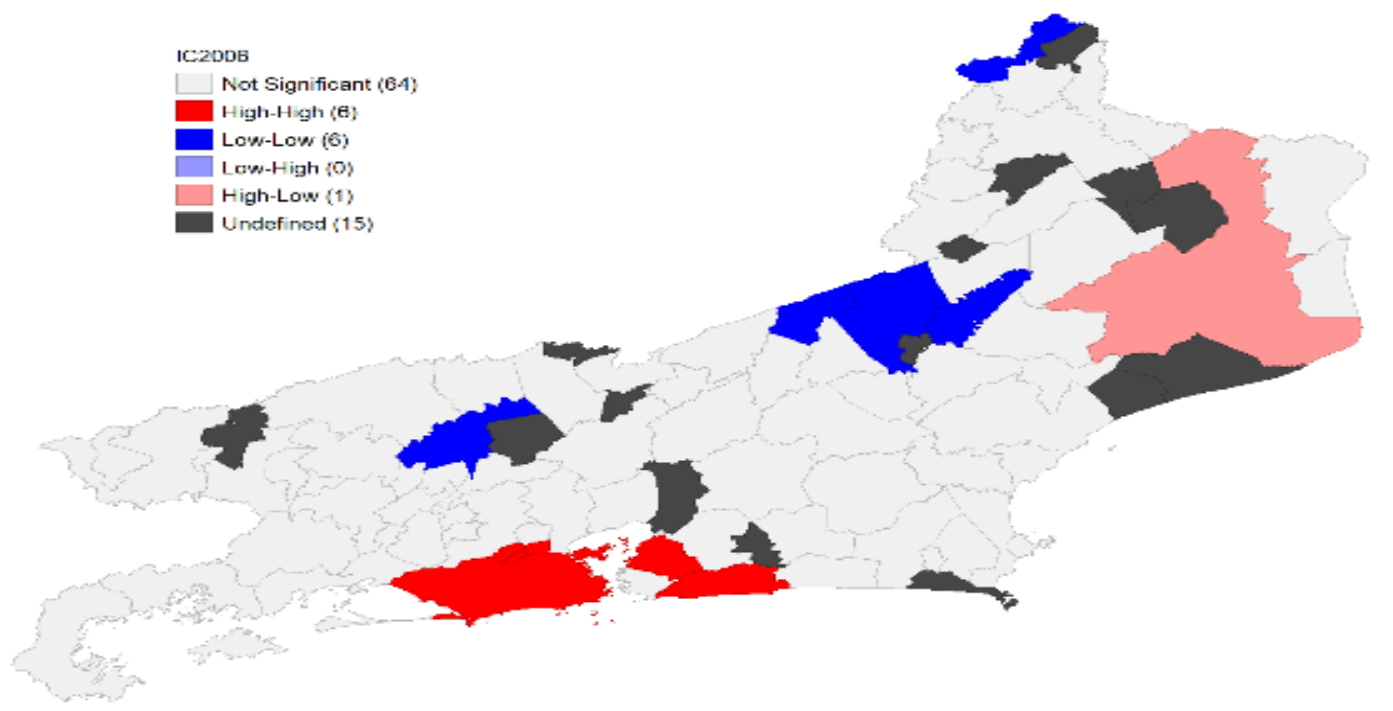

Fonte: elaborada pelos autores a partir do software GeoDa.

A tonalidade azul representa a formação de clusters do tipo baixo-baixo, enquanto a cor vermelha sinaliza os clusters padrão alto-alto. A tonalidade rosa refere-se às aglomerações do tipo alto-baixo e a cor lilás, aos clusters baixo-alto. As áreas de cor cinza não tiveram formação de clusters estatisticamente significativos. Por fim, as áreas representadas pela cor preta nos mapas dizem respeito aos municípios com informações faltantes, conforme explicitado na subseção 3.1 do presente trabalho. 
As informações contidas na Figura 5 tornam passível de observação a formação de clusters padrão alto-alto na Região Metropolitana do estado no ano de 2006, contemplando os municípios de Maricá, Mesquita, Nilópolis, Rio de Janeiro, São Gonçalo, São João de Meriti. Ademais, no mesmo ano formou-se, também, clusters do tipo alto-baixo na região Norte Fluminense, a saber, no município de Campos dos Goytacazes. E outro do tipo baixo-baixo nos municípios de Cantagalo, Carmo, Cordeiro, Porciúncula, São Sebastião do Alto e Vassouras.

Os municípios acometidos pelo padrão de clusters alto-alto neste índice fazem parte da Região Metropolitana do estado do Rio de Janeiro. Esses municípios, conforme explicitado na subseção 4.1, contam com alta densidade demográfica e elevados níveis de PIB per capita. Esses resultados, portanto, corroboram novamente com as proposições de Becker (1968) e Oliveira (2005). Além disso, a grande dimensão desses municípios, juntamente com a proximidade entre eles, pode ter facilitado a fuga dos criminosos e o trânsito deles entre toda essa região, visto que uma alta densidade populacional aumenta o anonimato dos criminosos. Já os municípios que constituem o padrão baixo-baixo localizam-se, principalmente, nas regiões Centro e Noroeste Fluminense. Esses municípios, além de contarem com uma extensão demográfica menor, também possuem uma menor dinâmica econômica.

No índice de 2010, conforme pode ser observado na Figura 6, foi possível verificar a formação de clusters do tipo alto-alto também na Região Metropolitana do estado, contemplando os municípios de Belford Roxo, Duque de Caxias, Maricá, Mesquita, Nilópolis, Nova Iguaçu, Rio de Janeiro, São Gonçalo e São João de Meriti. Os clusters do tipo baixo-baixo estão localizados, principalmente, nas regiões Serrana, Centro Fluminense e Noroeste Fluminense, onde tem-se os municípios de Bom Jardim, Cantagalo, Cordeiro, Duas Barras, Itaocara, Itaperuna, Porciúncula, São Fidélis, São Sebastião do Alto, Sapucaia, Sumidouro, Teresópolis e Vassouras. Observou-se, ainda, no período a formação de um cluster do tipo baixo-alto no município de Seropédica. 
Figura 6 - Clusters espaciais do $I C_{m}$ nos municípios do Rio de Janeiro (2006)

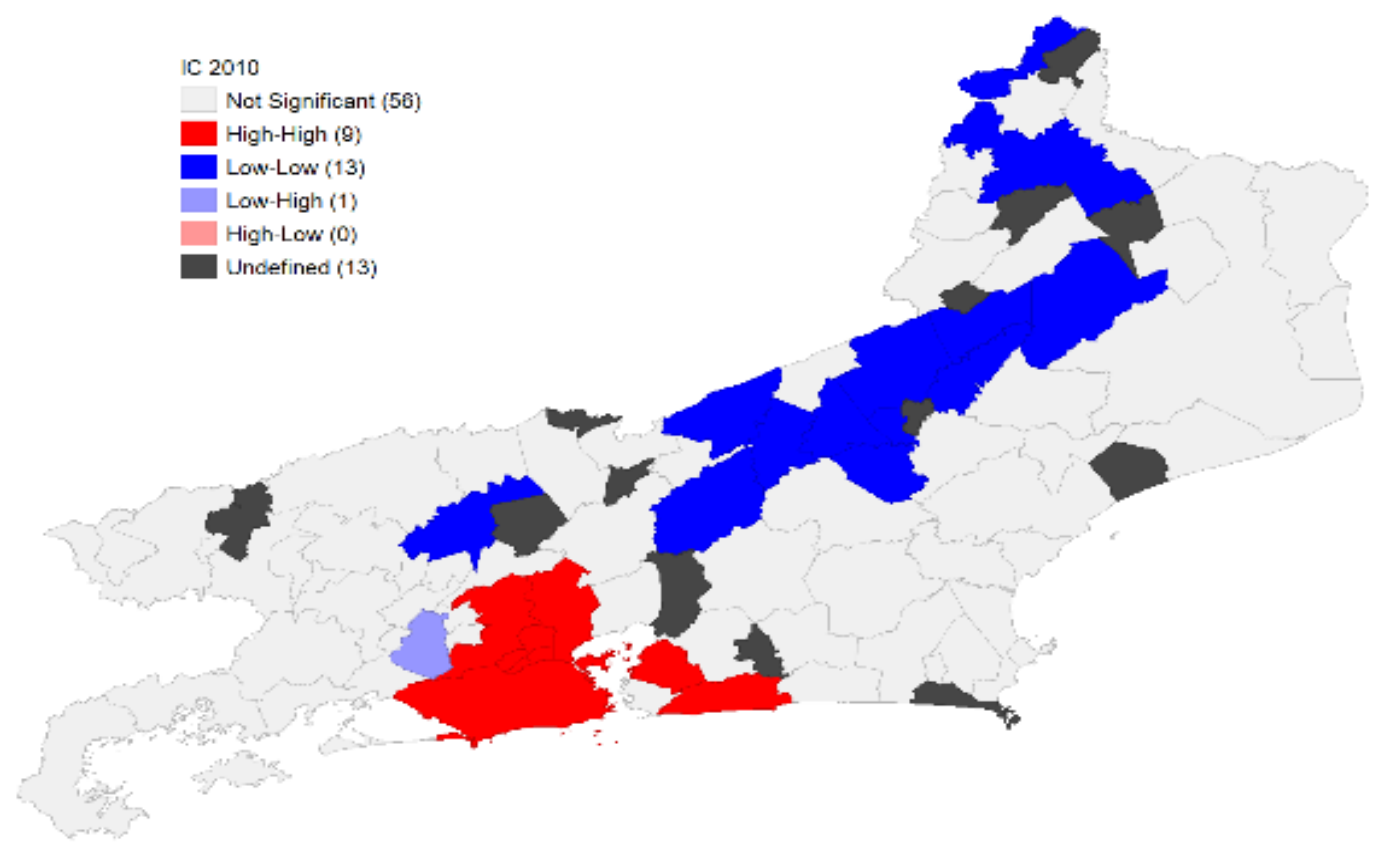

Fonte: elaborada pelos autores a partir do software GeoDa.

Em 2016, os clusters padrão baixo-baixo formaram-se nos municípios de Cantagalo, Carmo, Duas Barras, Itaocara, Mendes, Nova Friburgo, Santa Maria Madalena, Santo Antônio de Pádua, São Sebastião do Alto, Sapucaia, Sumidouro, Teresópolis, Três Rios e Vassouras. Já os padrões alto-alto foram observados na Região Metropolitana novamente, contemplando os municípios de Belford Roxo, Duque de Caxias, Maricá, Mesquita, Nilópolis, Nova Iguaçu, Rio de Janeiro, São Gonçalo, São João de Meriti e Seropédica. No entanto, uma diferença neste ano foi a formação de um cluster do tipo alto-baixo no município de Cordeiro. Ou seja, o município possui alto índice de criminalidade e está circundado por municípios com um baixo índice de criminalidade. 
Figura 7 - Clusters espaciais do $I C_{m}$ nos municípios do Rio de Janeiro (2016)

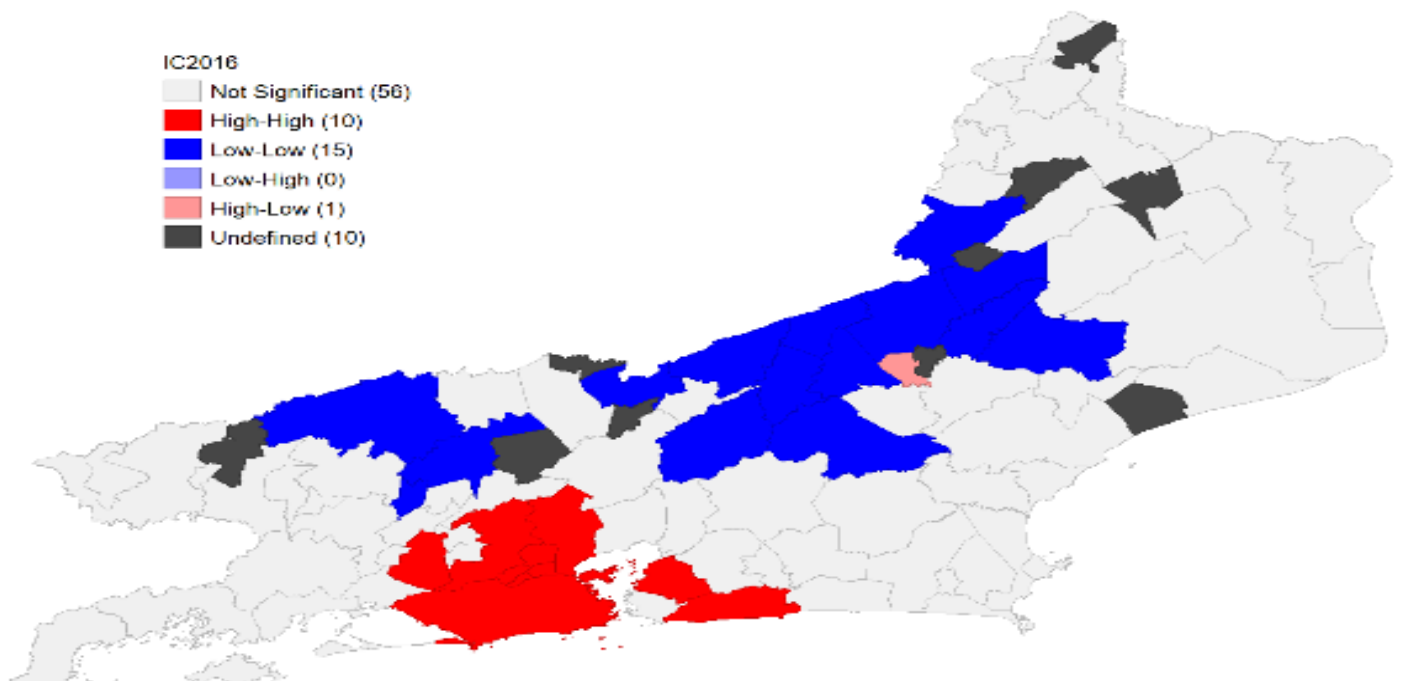

Fonte: elaborada pelos autores a partir do software GeoDa.

A questão que envolve o município de Cordeiro ocorre de forma interessante. A incidência de um alto índice de criminalidade nesta localidade foge da ideia proposta por Oliveira (2005) da relação entre crime a grandes cidades. De acordo com as estimativas populacionais do IBGE (2016), o município de Cordeiro possui apenas cerca de 21.158 habitantes, apesar de parecer um resultado não esperado, pode ter sido justamente a baixa densidade demográfica do município que fez o índice encontrado ter sido alto. Em termos absolutos, as ocorrências criminais foram abaixo dos valores encontrados para muitos outros municípios. No entanto, ao relativizar pela população, foi possível obter uma alta incidência de criminalidade dados os padrões locais.

Os resultados obtidos demonstraram, então, que os padrões alto-alto se deram sobretudo na Região Metropolitana, conforme esperado, dadas as características dessa área. No entanto, também foi possível observar uma certa interiorização da criminalidade na medida em que esta não ficou restrita apenas à capital, corroborando com a hipótese de Waiselfisz (2011). Conforme comentado na Seção 1 do presente estudo e argumentado por Uchôa e Menezes (2012), a repressão acometida sobre alguns tipos de crimes (sobretudo o tráfico de drogas) na capital pode ter contribuído para que o crime possivelmente se "espalhasse" pelo estado. Ademais, a instalação das Unidades de Polícia 
Pacificadora (UPP's) no Rio de Janeiro, em 2008, também pode ter influenciado no comportamento do crime.

\section{Conclusão}

Este artigo teve por objetivo construir e analisar três diferentes índices gerais de criminalidade para os municípios do Rio de Janeiro. Foram construídos índices para os anos de 2006, 2010 e 2016 que evidenciaram um ponto forte em comum: o crime fluminense é concentrado em centros urbanos de elevada renda per capita, com efeitos que se expandem para municípios vizinhos. No entanto, cabe mais uma vez reforçar que os índices foram construídos com o intuito de analisar três distintos cenários de forma isolada, e não de compará-los, embora os resultados apontem para pontos de convergência.

A prática criminosa no Rio de Janeiro provavelmente se aprimora de forma que novas práticas são aprendidas, ou seja, há ganhos de experiência, que acabam por ampliar o arsenal de atividades ilícitas, o que é intensificado graças à autocorrelação espacial do crime, que esteve presente nos índices dos três anos analisados. Esse resultado pode sugerir que quanto mais rápida a retirada do criminoso do ambiente do crime, de forma que ele mantenha pouco contato com outros infratores, possivelmente melhor se dará o combate à evolução e ampliação de atuação da prática criminosa, atividade que deve ser combinada também com medidas de prevenção a práticas ilícitas, o que pode ser testado em trabalhos futuros. Assim, é preciso fazer um questionamento a respeito de como se dão as atuais medidas que visam punir os atos ilícitos, não somente no estado do Rio de Janeiro, mas também no Brasil, de modo a encontrar formas mais eficazes.

Os resultados obtidos na análise exploratória dos dados confirmam também a dependência espacial do crime fluminense. Os clusters formados nos diferentes anos indicaram que municípios de alta criminalidade são circundados por municípios de alta criminalidade, com a ocorrência também do inverso. Esse resultado pode apontar para medidas de segurança pública ineficazes no estado, baseadas unicamente em formas de repressão que acabam dispersando o crime ao invés de efetivamente combatê-lo.

Dentre as limitações do estudo, destacam-se a impossibilidade, dado o método utilizado, de comparação dos índices gerados, bem como a falta de informações acerca das ocorrências criminosas em todos os municípios do estado 
do Rio de Janeiro. Para que trabalhos futuros possam analisar a questão espacial da criminalidade em todo o estado, faz-se necessário que os institutos e agências de pesquisa tenham acesso e disponibilizem as informações para o público. E para que comparações entre índices sejam realizadas, sugere-se o uso da AF dinâmica ou longitudinal.

Por fim, espera-se que os formuladores de políticas públicas se atentem ao fenômeno da dependência espacial do crime, de forma a se evitar o prolongamento da alta concentração criminosa em mais municípios. Para isso, faz-se necessário que os gestores de segurança pública do Rio de Janeiro destaquem seu olhar para os demais municípios além da Região Metropolitana, além disso, recomenda-se a atualização de soluções das políticas de segurança pública, através de maior foco no bem-estar da população de todo o estado.

\section{Referências}

ALMEIDA, E. Econometria espacial. Campinas: Alínea, 2012.

ANSELIN, L. Local indicators of spatial association - LISA. Geographical Analysis, v. 27, n. 2, p. 93-115, 1995.

ANDRADE, M.; LISBOA, M. Mortalidade nos estados do Rio de Janeiro, São Paulo e Minas Gerais. Estudos Econômicos, v. 31, n. 1, p. 5-56, 2001.

ARAÚJO JÚNIOR, A.; FAJNZYLBER, P. O que causa a criminalidade violenta no Brasil? Uma análise a partir do modelo econômico do crime: 1981 a 1996. Texto para discussão. Belo Horizonte: Universidade Federal de Minas Gerais - Centro de Desenvolvimento e Planejamento Regional, 2001.

BATELLA, W.; DINIZ, A. Análise especial dos condicionantes da criminalidade violenta no estado de Minas Gerais. Sociedade \& Natureza, v. 22, n. 11, p. 151$163,2010$.

BECKER, G. Crime and punishment: an economic approach, Journal of Political Economy, v. 76, n. 2, p. 169-217, 1968.

BECKER, K.; KASSOUF, A. L. Uma análise do efeito dos gastos públicos em educação sobre a criminalidade no Brasil. Economia e Sociedade, v. 26, n. 1, p. 215-242, 2017. 
CANTOR, D.; LAND, K. Unemployment and crime rates in the post-World War II United States: a theoretical and empirical analysis. American Sociological Review, v. 50, p. 317-332, 1985.

CASTRO, T.; SILVEIRA, I.; LÍRIO, V.; CORONEL, D.; SILVA, R. Perfil da criminalidade nos municípios de Minas Gerais. Espacios, v. 35, n. 12, p. 16, 2014.

CERQUEIRA, D.; LOBÃO, W. Determinantes da criminalidade: uma resenha dos modelos teóricos e resultados empíricos. Rio de Janeiro: IPEA, 2004.

CERQUEIRA, D.; MOURA, R. Oportunidades para o jovem no mercado de trabalho e taxas de homicídio no Brasil. In: ENCONTRO NACIONAL DE ECONOMIA (ANPEC). [Anais]. Florianópolis, 2015.

EHRLICH, I. Participation in illegitimate activities: a theoretical and empirical investigation. Journal of Political Economy, v. 81, n. 3, p. 521-565, 1973.

ENTORF, H.; SPENGLER, H. Socioeconomic and demographic factors of crime in Germany: evidence from panel data of the German states. International Review of Law and Economics, v. 20, n. 1, p. 75-106, 2000.

FÁVERO, L.; BELFIORE, P. Manual de análise de dados. Rio de Janeiro: Elsevier, 2017.

FERREIRA JÚNIOR, S.; BAPTISTA, A.; LIMA, J. A modernização agropecuária nas microrregiões do Estado de Minas Gerais. Revista de Economia e Sociologia Rural, v.42, n. 1, p.73-89, 2004.

FÓRUM BRASILEIRO DE SEGURANÇA PÚBLICA. Anuário Brasileiro de Segurança Pública 2019. Brasília, 2019.

FUNDAÇÃO CEPERJ. Ceperj lança novo mapa alterando a Região Metropolitana do Rio de Janeiro. Rio de Janeiro, 2019.

GOMES, C.; EVANGELISTA, T.; LIMA, R.; PARRÉ, J. Determinantes do crime nos municípios de minas gerais e seus possíveis spillovers espaciais. Economia Ensaios, v. 31, n. 2, p. 201-228, 2017.

HAIR JUNIOR, J.; BLACK, B.; BABIN, B.; ANDERSON, R.; TATHAM, R. Análise multivariada de dados. Bookman Editora, 2009.

MENEZES, T.; UCHOA, C. Spillover espacial da criminalidade: uma aplicação de painel espacial, para os estados brasileiros. In: ENCONTRO NACIONAL DE ECONOMIA, 40, 2012, Anais [...] Porto de Galinhas, 2012. 
MINGOTI, S. Análise de dados através de métodos de estatística multivariada: uma abordagem aplicada. Belo Horizonte: Editora UFMG, 2005.

MISSE, M. Crime organizado e crime comum no Rio de Janeiro: diferenças e afinidades. Revista de Sociologia Política, Curitiba, v. 19, n. 40, p.13-25, 2011.

OLIVEIRA, C. Análise espacial da criminalidade no Rio Grande do Sul. Revista de Economia, v. 34, n. 3, p. 35-60, 2008.

PEIXOTO, B.; MORO, S.; ANDRADE, M. Criminalidade na região metropolitana de Belo Horizonte: uma análise espacial. Belo Horizonte: Centro de Desenvolvimento e Planejamento Regional (Cedeplar), 2004.

PHILLIPS, J.; LAND, K. The link between unemployment and crime rate fluctuations: an analysis at the county, state, and national levels. Social Science Research, v. 41, n. 3, p. 681-694, 2012.

PLASSA, W.; PARRÉ, J. A violência no estado do Paraná: uma análise espacial das taxas de homicídios e de fatores socioeconômicos. Economia $e$ Desenvolvimento, v. 31, n. 1, p. 1-16, 2019.

PROCÓPIO, D.; TOYOSHIMA, S. Fatores associados à criminalidade violenta no Brasil. Revista Análise Econômica, v. 35, n. Especial, p. 263-288, 2017.

RESENDE, J.; VIEGAS, M. Crime social, castigo social: desigualdade de renda e taxas de criminalidade nos grandes municípios brasileiros. Estudos Econômicos, v. 41, n. 1, p. 173-195, 2011.

SALGADO, L. Determinantes da criminalidade: uma análise sobre as regiões norte e noroeste fluminense e baixadas litorâneas. 2017. 67 f. Monografia (Graduação em Ciências Econômicas). Universidade Federal Fluminense. Campos dos Goytacazes, Rio de Janeiro, 2017.

SARAIVA, M.; CONCEIÇÃO, O.; FRANÇA, M. Os determinantes da criminalidade nos municípios gaúchos: evidências de um modelo econométrico espacial. In: ENCONTRO DE ECONOMIA GAÚCHA, 8. Anais [...] Porto Alegre, 2016.

SASS, K.; PORSSE, A., SILVA, E. da. Determinantes das taxas de crimes no Paraná: uma abordagem espacial. Revista Brasileira de Estudos Regionais e Urbanos, v. 10, n. 1, p. 44-63, 2016.

SHIKIDA, P. Crimes violentos e desenvolvimento socioeconômico: um estudo para o estado do Paraná. Direitos Fundamentais \& Justiça, v. 2, n 5, p. 144-161, 2008. 
SILVA JÚNIOR, I. Impactos das políticas de segurança sobre a difusão da criminalidade entre as cidades: uma aplicação dos modelos de Econometria Espacial. 2016. 55 f. Dissertação (Mestrado em Economia). Universidade Federal de Pernambuco, Recife, Pernambuco, 2016.

SZWARCWALD, C.; EUCLIDES, A. Mortalidade por armas de fogo no estado do Rio de Janeiro, Brasil: uma análise espacial. Revista. Panamericana de Salud Pública, v. 4, n. 3, p. 161-170, 1998.

WAISELFISZ, J. Mapa da violência 2012: os novos padrões da violência homicida no Brasil. São Paulo: Instituto Sangari, 2011. 